\title{
MicroRNAs as Diagnostic Tools in Hepatocellular Carcinoma
}

\author{
Jessica Evangelista ${ }^{1}$, Elisa Zaninotto ${ }^{2}$, Annalisa Gaglio ${ }^{3}$, Michele Ghidini ${ }^{4, *(1)}$ and Lucrezia Raimondi ${ }^{5}(\mathbb{D}$ \\ 1 Thoracic Surgery, Fondazione Policlinico Universitario A. Gemelli IRCCS (Istituto di Ricovero e Cura a \\ Carattere Scientifico), 00168 Rome, Italy; jessicaevangelista@policlinicogemelli.it \\ 2 Section of Oncology, Department of Medicine, University of Verona School of Medicine and Verona \\ University Hospital Trust, 37134 Verona, Italy; elisa.zaninotto@gmail.com \\ 3 Department of Translational Medicine, Università Del Piemonte Orientale, 28100 Novara, Italy; \\ annalisa.gaglio1@gmail.com \\ 4 Medical Oncology Unit, Fondazione IRCCS (Istituto di Ricovero e Cura a Carattere Scientifico) Ca' Granda \\ Ospedale Maggiore Policlinico, Via Della Commenda 19, 20122 Milan, Italy \\ 5 U.O.C. Territorial Oncology of Aprilia, Sapienza University of Rome, 04011 Aprilia, Italy; \\ lucrezia.raimondi@uniroma1.it \\ * Correspondence: michele.ghidini@policlinico.mi.it
}

Citation: Evangelista, J.; Zaninotto,

E.; Gaglio, A.; Ghidini, M.; Raimondi,

L. MicroRNAs as Diagnostic Tools in Hepatocellular Carcinoma.

Gastrointest. Disord. 2021, 3, 237-246.

https://doi.org/10.3390/

gidisord3040022

Academic Editor: Takuji Tanaka

Received: 14 September 2021

Accepted: 10 November 2021

Published: 12 November 2021

Publisher's Note: MDPI stays neutral with regard to jurisdictional claims in published maps and institutional affiliations.

\begin{abstract}
Liver cancer is the fourth leading cause of cancer-related deaths worldwide, with hepatocellular carcinoma (HCC) accounting for approximately $80 \%$ of all liver cancers. The serum concentration of alpha-fetoprotein (AFP) is the only validated biomarker for HCC diagnosis. MicroRNAs (miRNAs) are small non-coding RNAs of 21-30 nucleotides playing a critical role in human carcinogenesis, with types of miRNAs with oncogenic (oncomiRs) or tumor suppressor features. The altered expression of miRNAs in HCC is associated with many pathological processes, such as cancer initiation, tumor growth, apoptosis escape, promotion of migration and invasion. Moreover, circulating miRNAs have been increasingly investigated as non-invasive biomarkers for HCC diagnosis. MiRNAs' expression patterns are altered in HCC and several single miRNAs or miRNAs panels have been found significantly up or downregulated in HCC with respect to healthy controls or non-oncological patients (cirrhotic or with viral hepatitis). However, any of the investigated miRNAs or miRNAs panels has entered clinical practice so far. This has mostly to do with lack of protocols standardization, small sample size and discrepancies in the measurement techniques. This review summarizes the major findings regarding the diagnostic role of miRNAs in HCC and their possible use together with standard biomarkers in order to obtain an early diagnosis and easier differential diagnosis from non-cancerous liver disease.
\end{abstract}

Keywords: microRNAs; HCC; hepatocellular carcinoma; diagnosis; prognosis

\section{Introduction \\ 1.1. Hepatocellular Carcinoma}

Liver cancer, with an estimated incidence of $>1$ million cases by 2025 , is the fourth leading cause of cancer-related deaths worldwide, making it a global health challenge [1]. Hepatocellular carcinoma (HCC) is the dominant type of liver cancer, accounting for approximately $80 \%$ of all liver cancers [2]. Despite the incidence rates are decreasing in some high-rate areas, primary liver cancer remains the second-most common cause of cancer mortality in many low-rate areas [3]. HCC is one of the few cancers with welldefined major risk factors and geographical differences in incidence reflect variations of the main causal factors of HCC [4]. Hepatitis B virus (HBV) and Hepatitis C virus (HCV) infection are the most prominent risk factors for hepatocarcinogenesis, although alcoholic liver disease (ALD), non-alcoholic steatohepatitis (NASH) and nonalcoholic fatty liver disease (NAFLD), associated with diabetes mellitus or metabolic syndrome, are becoming the leading etiology of HCC, particularly in the West [5-7]. Despite recent progress in 
HCC therapy, the 5-year survival rate for late-stage HCC remains poor, because of its late diagnosis, resistance to therapy and high frequency of recurrence [8].

\subsection{Diagnosis}

The diagnosis of HCC, usually based on non-invasive criteria, is currently challenged by the need for molecular characterization of the tumor using tissue or liquid biopsies in clinical practice. Although clinical studies are focusing on biomarker discovery, the only blood-based biomarker currently accepted and validated for HCC is alpha-fetoprotein (AFP) [9].

The serum concentration of AFP is the most commonly used marker for early diagnosis, monitoring and recurrence of HCC, albeit its sensitivity is around $40 \%$ : most tumors do not produce AFP at all or only in advanced stages and on the other hand, elevation of AFP is found in patients with chronic liver diseases or acute viral hepatitis too. Given these limitations, HCC diagnosis should be performed using a combination of imaging (ultrasonography) and serum biomarkers [10,11].

HCC harbors a pathognomonic radiological presentation, often crucial for diagnosis. Compared with the background liver, the differential blood supply of the tumor, unbalanced in favor of arterial perfusion over portal perfusion, is responsible of distinctive radiological enhancement pattern on contrast-enhanced magnetic resonance imaging (MRI) of HCC. Hence, HCC lesions are characterized by hyperenhancement in the arterial phase (wash-in) and hypoenhancement (wash-out) in the venous/delayed phases of acquisition.

If these features are evident, the diagnosis of HCC can be obtained in most cases radiologically, without the need for biopsy confirmation.

According to the main European guidelines, abdominal ultrasonography (US) is the most commonly recommended surveillance modality of high-risk patients (affected by cirrhosis or chronic hepatitis infection) $[10,11]$.

Early diagnosis of suspicious lesions is of utmost importance, in order to recognize promptly and treat adequately every lesion and to justify the cost-benefit balance of the surveillance. Therefore, the improvement of accurate diagnostic tools is in this setting highly desirable. For diagnosis of lesions $\geq 10 \mathrm{~mm}$ in diameter, both contrast-enhanced MRI and quadruple-phase Computer Tomography should be performed [10,11]; the use of Contrast Enhanced-Ultrasound (CEUS) is still controversial despite recent encouraging results [12,13]. Lesions smaller than $10 \mathrm{~mm}$ are too small to be properly characterized and should be monitored at regular intervals ( 3 to 4 months). MRI had the highest per-lesion sensitivity for HCC, superior to CT, $80 \%$ vs. $68 \%$, respectively [14]. In the current scenario of non-invasive diagnosis of HCC, the role of hepatobiliary MRI contrast agents or diffusion weighted MRI or novel positron emission tomography (PET) radiotracers remains unclear, needing to be further validated before being included in the diagnostic algorithm.

In case of an unclear lesion or an atypical pattern, a second imaging method should be considered; if the diagnostic doubt persists, a biopsy with intra- and extra-injury sampling is indicated [10], especially for lesions $<2 \mathrm{~cm}$, which more rarely show the typical pattern [15]. The decision to proceed with a biopsy should take into account the complications associated with the procedure, the possibility of inadequate sampling and the risk of tumor seeding [16]. In case of a negative biopsy result, if well-differentiated HCC is suspected, the repetition of the biopsy may be indicated, reducing the risk of false negative [17]. (Figure 1). Staging of HCC is based on the use of CEMRI, showing high sensitivity in detecting small intrahepatic nodules, or of CECT, including chest imaging, in advanced HCC [1]. 


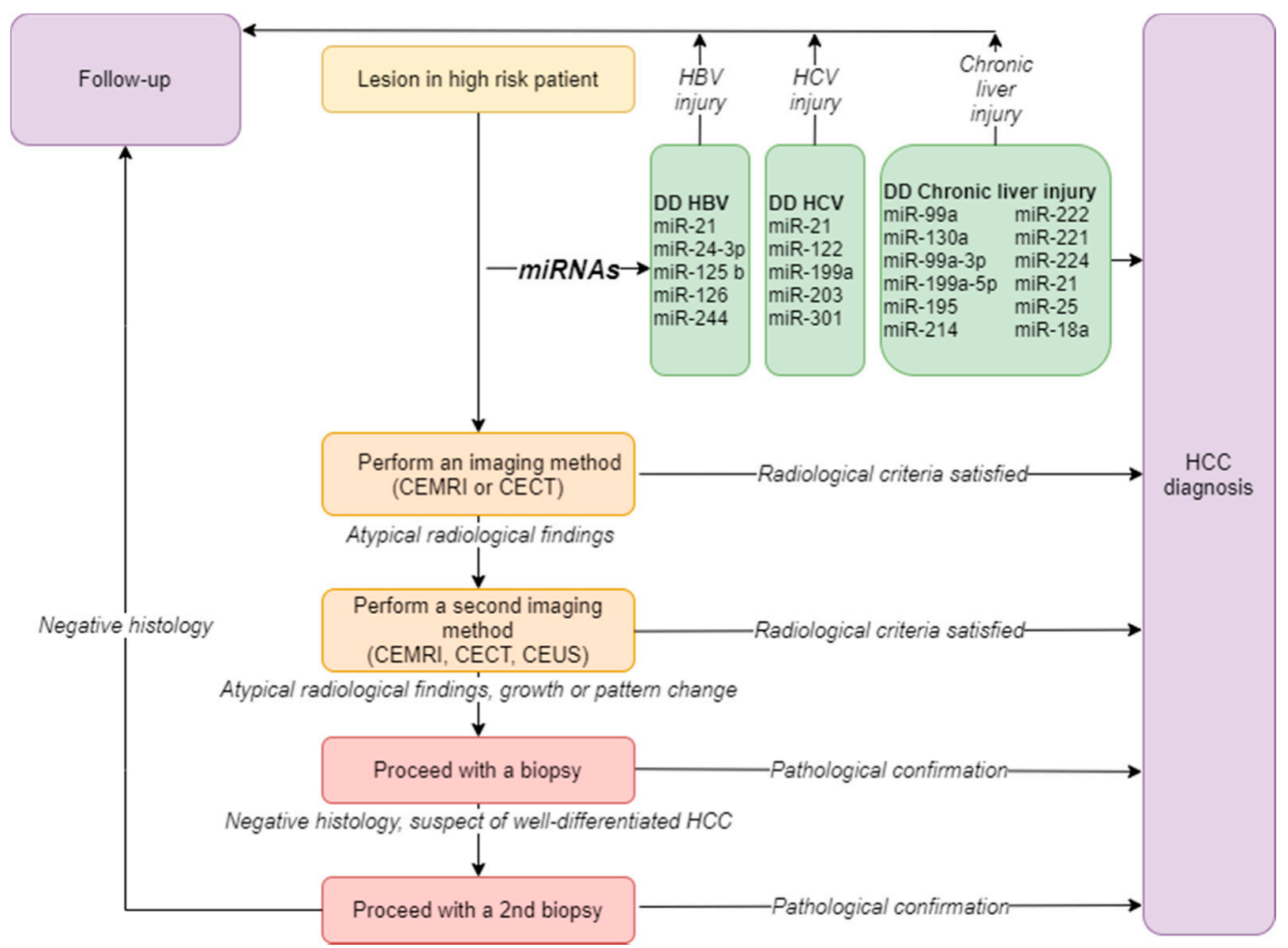

Figure 1. HCC diagnostic flow diagram. According to current guidelines, in case of detection of a suspicious liver lesion, imaging is the main diagnostic tool, followed by pathological diagnosis in case of persistence of atypical characteristics. The introduction of microRNAs analysis in the diagnostic algorithm would allow a more precise differential diagnosis between HCC, HBV, HCV or chronic liver damage. Legend: CECT: Contrast Enhanced-Computer Tomography; CEUS: Contrast Enhanced-Ultrasound; CEMRI: Contrast Enhanced Magnetic Resonance Imaging; DD: differential diagnosis; miRNA: microRNA.

\subsection{MicroRNAs}

MicroRNAs (miRNAs) are small non-coding RNAs of 21-30 nucleotides in length, highly conserved across different animal species, that have been increasingly investigated in the last few years for their ability to modulate more than 15,000 genes [18]. In the nucleus, RNA polymerase II generally transcribes miRNAs genes in order to generate primary miRNA transcripts (pri-miRNAs). Pri-miRNAs consists of one or more hairpin structures that finally produce on or more functional miRNAs. Transcription is an important step for miRNA expression. Indeed, promoters of miRNAs' genes harbor many features in common with protein-coding genes, such as presence of TATA box and GpG islands [19]. A single miRNA can modulate more than 200 mRNAs [20]. Despite the important roles of miRNAs in the modulation of mRNA expression are well established, their precise functions remain elusive. Circulating miRNAs have been increasingly investigated as non-invasive biomarkers of disease, including liver disease. By modulating the expression of approximately $30 \%$ of all human genes, many of which are tumor-associated or located in regions of instability in the genome, miRNAs play a critical role in human carcinogenesis, with types of miRNAs with oncogenic (oncomiRs) or tumor suppressor features [21]. While oncomiRs induce carcinogenesis by inhibiting the expression of tumor suppressors, tumor suppressor miRNAs inhibit oncogene expression in normal cells and are lacking in cancer cells [22]. Data on the expression of miRNAs mainly come from real time polymerase chain 
reaction (PCR)-based and microarray-based profiling. More recently, new technologies such as next generation sequencing (NGS) have led to the identification of new miRNAs, providing also a detailed characterization of miRNAs isoforms $[23,24]$.

\subsection{MicroRNAs and HCC}

The relationships between miRNAs and HCC have been described by several studies and potential miRNA biomarkers for HCC diagnosis and treatment have been identified. The altered expression of miRNAs in HCC is associated with many pathological processes, such as cancer initiation, tumor growth, apoptosis escape, promotion of migration and invasion [25]. Normal liver tissues express a limited number of miRNAs (e.g., miR-199a and miR-122) [26], while HCC often presents loss of these miRNAs together with overexpression of others (e.g., miR-21, miR-221/222 and miR-517) [27-29]. Polymorphisms in miRNAs' genes can determine production of mature miRNA forms with liver carcinogenic potential [25]. For example, a G > C polymorphism in the stem region of miR-146a is associated with HCC development [30]. In addition, other mechanisms through which miRNAs' expression is modulated during liver carcinogenesis are chromosomal rearrangement, promoter methylation, transcriptional induction and delivery between cells trough exosomes [25].

The major clinical implications of miRNAs in HCC include the diagnostic and prognostic role for the disease together with the predictive role of response to anticancer treatment. Moreover, several clinical trials testing miRNAs-based therapeutics are ongoing [25].

This review summarizes the major findings regarding the diagnostic role of miRNAs in HCC and their possible use together with standard biomarkers in order to obtain an early diagnosis and easier differential diagnosis from non-cancerous liver disease.

\section{The Diagnostic Role of microRNAs in HCC}

For decades, serum $\alpha$-fetoprotein (AFP), in association with hepatic ultra-sound imaging, has been the most commonly used serological biomarker for HCC detection and surveillance, even if with poor specificity [31]. Given the need for sensitive and specific biomarkers able to be evaluated in readily accessible tissues, several studies have reported the potential role of circulating miRNAs, since they circulate in a highly stable cell-free form in the circulation, as predictive and diagnostic non-invasive biomarkers in this setting [32]. Aberrant expression of circulating miRNAs has been reported in chronic liver injury, liver inflammation and HCC (Table 1) and to date, discovering a panel of miRNAs able to distinguish HCC from non-cancerous liver disease is therefore needed $[33,34]$.

In regions where hepatitis $B(\mathrm{HBV})$ remains endemic such as Africa, the Western Pacific region and Asia, circulating miR21, miR-24-3p, miR125b, miR-126 and miR-224 can be used to distinguish HCC from HBV [35], as well as miR-21, miR-122, miR-199a, miR-203 and miR-301 can be used to identify patients with HCC from ones with chronic hepatitis C [36-40]. Although it is still difficult to differentiate chronic liver injury from HCC with high accuracy, six most consistently downregulated miRNAs (miR99a, miR-130a, miR-199a-3p, miR-199a-5p, miR-195and miR-214) and six upregulated miRNAs (miR-222, miR-221, miR-224, miR-21, miR-25 and miR-18a) were identified in different profiling studies comparing miRNA dysregulation in HCC tissues and corresponding non-tumor liver tissues [41,42]. The serum level of miR-17-5p was down-regulated in a group of HCC resected patients. On the contrary, it was found upregulated in the HCC relapsed group and significantly associated with worse metastasis status and TNM stage [43].

Evaluation of circulating microvesicles and exosomes may be useful in early diagnosis of HCC, as well. Exosomes were characterized based on morphological aspect, molecular weight, protein markers CD63, CD9, and CD81, and miR-21-5p and miR-92a-3p exosomal expression levels. Expression profile analysis indicated that miR-21-5p was upregulated $(p=0.017)$, and miR-92a-3p was downregulated $(p=0.0005)$ in plasma-derived exosomes from HCC subjects, regardless of patient characteristics patient characteristics. The clinical risk prediction model for HCC diagnosis based on AFP only had an AUROC score of 
0.72 , while it improved significantly to 0.85 after the integration of AFP with the exosomal expression of miR-21-5p and miR-92a-3p [44].

Moreover, different miRNAs have been reported to target several key driver genes in HCC. The miR-99 family, with its three members miR-99a, miR-99b and miR-100, has been reported to have potential role as tumor suppressor in multiple types of cancer $[45,46]$. MiR-99a, involved in blocking cell cycle at G1/S transition, is the sixth most bountiful microRNA in the miRNome of normal human liver and it is significantly down-regulated in HCC [47]. Decreased expression of miR-99a, which seemed independent of HCV or HBV infection, correlates with worse prognosis of HCC patients [48]. Lower miR-130a levels, associated with the better overall survival rates of HCC patients, have been associated with a decreased inhibition of the proliferation, migration and invasion of HCC cells by targeting Rho-associated kinases 2 (ROCK2) [49,50]. MiR-199a-3p and miR-199a-5p are consistently decreased in HCC patients, correlating with poor survival [51]. Remarkably, miR-199a-5p downregulation increased autophagy activation, inducing cell proliferation [52,53]. Moreover, recent studies revealed that HCC growth seems to be suppressed by miR-199a/b-3p through inhibiting PAK4/Raf/MEK/ERK pathway [54]. MiR-195 inhibits the invasion, migration and epithelial-mesenchymal transition of HCC cells with the decrease of E-cadherin expression and increase of vimentin expression and is significantly downregulated in HCC patients [55]. Lower miR-214 expression levels correlate with the hypervascularity and portal vein invasion, hallmarks of HCC, and with the increase of $\beta$-catenin, resulting in the upregulation of cyclinD1, c-Myc and Lymphoid Enhancer Binding Factor 1 [56]. Moreover, miR-214 indirectly targets CTNNB1 via suppressing the enhancer of zeste homologue 2 (EZH2), a driver-mutation gene in HCC progression, and it is associated with the invasion of HCC cells [57]. High circulating miR-18a expression levels promotes HCC cell migration augmenting HCC proliferation [58]. Similarly, upregulation of miR-21, by activating the pyruvate dehydrogenase kinase 1 (PDK1)/AKT pathway and downregulating the expression of the tumor suppressor phosphatase and tensin homolog (PTEN) promotes cancer cell migration and invasion with secretion of angiogenic molecules by cancer cells [59]. MiR-21 and mi-R25 levels permit the differentiation of HCC from chronic hepatitis with $61.1 \%$ sensitivity and $83.3 \%$ specificity and to distinguish between HCC and healthy controls showing a sensitivity of $86.6 \%$ and specificity of $79.5 \%$ [60].

MiR-221, miR-222 and miR-224 are the most highly deregulated miRNAs in HCC tissues. MiR-221 correlates with tumor size and tumor stage; patients with higher serum miR-221 levels show poor overall survival with shorter time to local recurrence than individuals with lower levels [61]. MiR-221 promotes HCC cells migration via targeting plant homeodomain finger 2 gene (PHF2), a cancer suppressor [62]. Mir-221, miR222 and miR224 are key oncogenic players in HCC when they are overexpressed or dysregulated and can serve as predictive factors for HCC patients' poor outcome $[28,63-66]$.

Circulating miR-122, a sensitive biomarker for liver injury, has been associated with both HCC and liver pathologies, even if with contradictory results [57]. Zhou et al. observed down-regulation of circulating miR-122 in mainly HBV-related HCC patients compared to healthy group, whereas $\mathrm{Xu}$ et al. and Qi et al. found miR-122 significantly upregulated in patients diagnosed with HCC [67-69]. Several target genes of miR-122a able to play a role in epithelial mesenchymal transition and tumorigenesis have been identified. The expression of cyclin G1, directly down-regulated by miR-122a, has been shown to be associated with genomic instability [70]. Deregulation of miR-122 in HCC patients has been correlated with AFP elevation, alanine aminotransferase increases and a more aggressive phenotype in HCC, with shorter recurrence-free and overall survival due to increased expression of Cut Like Homeobox 1 (CUX1), another direct target of miR-122 [71]. Moreover, increased serum levels of miR-122 have been described in NAFLD and decreased levels have been noted in liver tissues of NASH patients [72]. Accordingly, miR-122 is a good candidate biomarker for early liver pathology, but not specifically for HCC [67]. Cheng et al. recently identified VEGF signaling pathway as one of the most represented miRNA-regulated pathways in HCC: overexpression of miR-146a and miR-638 
has been showed to repress angiogenesis by reducing VEGF secretion, on the other hand lower miR-338-3p levels have been related to promote angiogenesis [73].

Table 1. Downregulated and upregulated circulating miRNAs in HCC.

\begin{tabular}{|c|c|c|c|c|}
\hline MiRNAs & Targets & Mechanisms & Expression & References \\
\hline miR-99a & PLK1, IGF-1R & & Down & [45-48] \\
\hline miR-130a & ROCK2 & metastasis & Down & {$[49,50]$} \\
\hline miR199a-3p & mTOR, PAK4, caveolin-2 & drug resistance, cell growth & Down & [50-54] \\
\hline miR199a-5p & DDR1, ATG7 & invasion, autophagy & Down & {$[52,53]$} \\
\hline miR-195 & cyclin D1, CDK6, E2F3, LATS2 & cell cycle, tumorigenesis, apoptosis & Down & [55] \\
\hline miR-214 & HDGF, $\beta$-catenin & cell growth, angiogenesis, metastasis & Down & {$[56,57]$} \\
\hline miR-18a & ER1a & proliferation & $\mathrm{Up}$ & {$[58]$} \\
\hline miR-21 & PTEN, RHOB, PDCD4 & metastasis, drug resistance & Up & [59] \\
\hline miR-25 & TRAIL & apoptosis & Up & [6] \\
\hline $\operatorname{miR}-221$ & p27, p57, ARNT, CDK inhibitors & $\begin{array}{c}\text { apoptosis, proliferation, } \\
\text { angiogenesis }\end{array}$ & Up & [61-64] \\
\hline miR-222 & p27, DDIT4 & tumorigenesis & Up & {$[28,65,66]$} \\
\hline $\operatorname{miR}-224$ & ATG5, SMAD4, autophagy, API5 & tumorigenesis, autophagy & Up & [64] \\
\hline miR-24-3p & Metallothionein 1M & proliferation, apoptosis & $\mathrm{Up}$ & [35] \\
\hline $\operatorname{miR} 122$ & BCL-w, ADAM17, WNT1 & $\begin{array}{c}\text { apoptosis, proliferation, } \\
\text { angiogenesis }\end{array}$ & Up/Down & {$[67-72,74]$} \\
\hline miR-17-5p & PTEN, GALNT7, vimentin & proliferation, invasion & Up/Down & [43] \\
\hline miR-92a-3p & PTEN, AKT/Snail & proliferation & Down & [44] \\
\hline
\end{tabular}

\section{Discussion}

The principal objective of HCC biomarker research is to find new molecules and optimize the use of the existing ones to diagnose the disease earlier in at-risk population. At the same time, the advent of new biomarkers may cause unnecessary testing and abuse of wasteful and needless follow-up examinations in absence of proper validation and algorithms for further management, given that only a small proportion of the at-risk population will eventually develop the disease [75].

The serum concentration of AFP is the only used marker for the diagnosis of HCC. Other serological biomarkers such as Golgi protein 73 (GP73), Glypican-3 (GPC3) and aldo-keto reductase family 1 member 10 (AKR1B10) appear promising but require further validation [75]. Osteopontin (OPN) has been reported as one of the most promising markers for HCC, as well. However, a meta-analysis demonstrated that OPN had comparable accuracy to AFP for HCC diagnosis, while the value of the combination AFP-OPN was not clear deserving further investigation [76]. MiRNAs can serve as diagnostic and prognostic tools in HCC and are being used as therapeutic targets, as well. MiRNAs participate in various processes such as HCC proliferation, apoptosis, invasion, metastasis, epithelial-mesenchymal transition, angiogenesis and drug resistance. Exosomes can vehiculate miRNAs between cells, and autophagy is a primary regulatory mechanism of miRNAs in HCC [77]. However, consistency of the results obtained with miRNAs is poor, with subsequent challenges in the process of clinical validation. Variability is one of the main reasons explaining the discrepancies observed in studies involving miRNAs in HCC. Indeed, miRNAs are found in higher concentrations in plasma rather than serum because of the platelet mediated degradation during the clotting process [75]. Moreover, the polymorphic sites of various miRNAs are associated with HCC, and prevalence of polymorphisms varies with ethnicity [78]. In addition, several miRNAs whose expression 
is increased in plasma and serum of HCC patients are expressed at lower levels in HCC tumor tissue compared with non-tumoral tissue.

A recent meta-analysis evaluated the diagnostic efficacy of miRNAs in distinguishing HCC at early stages from healthy individuals. A total of 34 studies were included, with 2747 HCC patients and 2053 healthy individuals. The diagnostic efficacy of serum and plasma-derived miRNAs was the same. Three different subgroups were compared, single miRNA, miRNAs' panel and multiple miRNAs. The miRNAs' panel had better diagnostic efficacy, with a sensitivity of $86 \%$ and specificity of $93 \%$. Among miRNAs that were initially found to be promising as diagnostic tools in HCC, miR-21 and miR-122 did not show a different expression in cancer patients in an analysis using RNA sequencing. Differently, miR-101-3p, miR-106b-3p and miR-1246 showed a good diagnostic accuracy, either individually or in combination, when evaluated in HCC patients versus healthy controls or cirrhotic patients [79].

Therefore, miRNAs could be used as valid biomarkers for HCC early diagnosis and prediction of prognosis. Moreover, understanding the regulatory mechanisms of miRNAs in HCC development and progression could allow the development of new molecular drugs. The main limitation of early-phase studies involving miRNAs is the scarce translation of experimental findings into clinical practice. Moreover, the technical reliability of miRNAs measurements in HCC diagnosis requires further assessments and development.

Future research of miRNAs in HCC should focus both on miRNAs taking part in HCC carcinogenesis and on miRNAs deregulated due to changes in the metabolic and structural profile of tumor cells. Therefore, consensus is necessary in order to reduce heterogeneity in techniques used, samples involved (tissue versus serum versus plasma) and groups compared to HCC patients (cirrhotic patients, patients with chronic hepatitis, healthy controls).

\section{Conclusions}

MiRNAs' expression patterns are altered in HCC. Significant progress has been made in the evaluation of circulating miRNAs as potential diagnostic biomarkers for HCC. However, any of the investigated miRNAs or miRNAs panels has entered clinical practice so far. This has mostly to do with lack of protocols standardization, small sample size and discrepancies in the measurement techniques. Larger and prospective studies are warranted in order to eliminate biases and possibly identify new useful biomarkers for HCC diagnosis, together or in place of AFP, which remains nowadays the only validated available biomarker.

Author Contributions: Conceptualization M.G. and J.E.; methodology, M.G.; resources, M.G.; data curation, L.R.; writing — original draft preparation, E.Z., J.E. and L.R.; writing—review and editing, L.R. and M.G.; visualization, M.G.; supervision, A.G.; project administration, M.G. All authors have read and agreed to the published version of the manuscript.

Funding: This research received no external funding.

Institutional Review Board Statement: Not applicable.

Informed Consent Statement: Not applicable.

Conflicts of Interest: The authors declare no conflict of interest.

\section{References}

1. Villanueva, A. Hepatocellular Carcinoma. Reply. N. Engl. J. Med. 2019, 381, e2. [CrossRef] [PubMed]

2. Aly, A.; Ronnebaum, S.; Patel, D.; Doleh, Y.; Benavente, F. Epidemiologic, humanistic and economic burden of hepatocellular carcinoma in the USA: A systematic literature review. Hepat. Oncol. 2020, 7, HEP27. [CrossRef] [PubMed]

3. Petrick, J.L.; Florio, A.A.; Loomba, R.; McGlynn, K.A. Have incidence rates of liver cancer peaked in the United States? Cancer 2020, 126, 3151-3155. [CrossRef] [PubMed]

4. But, D.Y.; Lai, C.L.; Yuen, M.F. Natural history of hepatitis-related hepatocellular carcinoma. World J. Gastroenterol. 2008, 14, 1652-1656. [CrossRef] [PubMed] 
5. $\quad$ Estes, C.; Razavi, H.; Loomba, R.; Younossi, Z.; Sanyal, A.J. Modeling the epidemic of nonalcoholic fatty liver disease demonstrates an exponential increase in burden of disease. Hepatology 2018, 67, 123-133. [CrossRef]

6. Kanwal, F.; Kramer, J.; Asch, S.M.; Chayanupatkul, M.; Cao, Y.; El-Serag, H.B. Risk of Hepatocellular Cancer in HCV Patients Treated With Direct-Acting Antiviral Agents. Gastroenterology 2017, 153, 996-1005. [CrossRef]

7. Zhang, G.; Li, R.; Deng, Y.; Zhao, L. Conditional survival of patients with hepatocellular carcinoma: Results from the Surveillance, Epidemiology, and End Results registry. Expert Rev. Gastroenterol. Hepatol. 2018, 12, 515-523. [CrossRef]

8. Altekruse, S.F.; Henley, S.J.; Cucinelli, J.E.; McGlynn, K.A. Changing hepatocellular carcinoma incidence and liver cancer mortality rates in the United States. Am. J. Gastroenterol. 2014, 109, 542-553. [CrossRef]

9. Singal, A.; Volk, M.L.; Waljee, A.; Salgia, R.; Higgins, P.; Rogers, M.A.; Marrero, J.A. Meta-analysis: Surveillance with ultrasound for early-stage hepatocellular carcinoma in patients with cirrhosis. Aliment. Pharmacol. Ther. 2009, 30, 37-47. [CrossRef]

10. European Association for the Study of the Liver. EASL Clinical Practice Guidelines: Management of Hepatocellular Carcinoma. J. Hepatol. 2018, 69, 182-236. [CrossRef]

11. Vogel, A.; Cervantes, A.; Chau, I.; Daniele, B.; Llovet, J.M.; Meyer, T.; Nault, J.C.; Neumann, U.; Ricke, J.; Sangro, B.; et al. Hepatocellular carcinoma: ESMO Clinical Practice Guidelines for diagnosis, treatment and follow-up. Ann. Oncol. 2019, 30, 871-873. [CrossRef]

12. Huang, J.Y.; Li, J.W.; Lu, Q.; Luo, Y.; Lin, L.; Shi, Y.J.; Li, T.; Liu, J.B.; Lyshchik, A. Diagnostic Accuracy of CEUS LI-RADS for the Characterization of Liver Nodules $20 \mathrm{~mm}$ or Smaller in Patients at Risk for Hepatocellular Carcinoma. Radiology 2020, 294, 329-339. [CrossRef] [PubMed]

13. Terzi, E.; Iavarone, M.; Pompili, M.; Veronese, L.; Cabibbo, G.; Fraquelli, M.; Riccardi, L.; de Bonis, L.; Sangiovanni, A.; Leoni, S.; et al. Contrast ultrasound LI-RADS LR-5 identifies hepatocellular carcinoma in cirrhosis in a multicenter restropective study of 1,006 nodules. J. Hepatol. 2018, 68, 485-492. [CrossRef] [PubMed]

14. Lee, Y.J.; Lee, J.M.; Lee, J.S.; Lee, H.Y.; Park, B.H.; Kim, Y.H.; Han, J.K.; Choi, B.I. Hepatocellular carcinoma: Diagnostic performance of multidetector CT and MR imaging-a systematic review and meta-analysis. Radiology 2015, 275, 97-109. [CrossRef]

15. Bolondi, L.; Gaiani, S.; Celli, N.; Golfieri, R.; Grigioni, W.F.; Leoni, S.; Venturi, A.M.; Piscaglia, F. Characterization of small nodules in cirrhosis by assessment of vascularity: The problem of hypovascular hepatocellular carcinoma. Hepatology 2005, 42, 27-34. [CrossRef]

16. Stigliano, R.; Marelli, L.; Yu, D.; Davies, N.; Patch, D.; Burroughs, A.K. Seeding following percutaneous diagnostic and therapeutic approaches for hepatocellular carcinoma. What is the risk and the outcome? Seeding risk for percutaneous approach of HCC. Cancer Treat. Rev. 2007, 33, 437-447. [CrossRef]

17. Cartier, V.; Crouan, A.; Esvan, M.; Oberti, F.; Michalak, S.; Gallix, B.; Seror, O.; Paisant, A.; Vilgrain, V.; Aube, C.; et al. Suspicious liver nodule in chronic liver disease: Usefulness of a second biopsy. Diagn. Interv. Imaging 2018, 99, 493-499. [CrossRef]

18. Chou, C.H.; Shrestha, S.; Yang, C.D.; Chang, N.W.; Lin, Y.L.; Liao, K.W.; Huang, W.C.; Sun, T.H.; Tu, S.J.; Lee, W.H.; et al. miRTarBase update 2018: A resource for experimentally validated microRNA-target interactions. Nucleic Acids Res. 2018, 46, D296-D302. [CrossRef] [PubMed]

19. Sun, J.; Lu, H.; Wang, X.; Jin, H. MicroRNAs in hepatocellular carcinoma: Regulation, function, and clinical implications. Sci. World J. 2013, 2013, 924206. [CrossRef]

20. Krek, A.; Grun, D.; Poy, M.N.; Wolf, R.; Rosenberg, L.; Epstein, E.J.; MacMenamin, P.; da Piedade, I.; Gunsalus, K.C.; Stoffel, M.; et al. Combinatorial microRNA target predictions. Nat. Genet. 2005, 37, 495-500. [CrossRef]

21. Si, W.; Shen, J.; Zheng, H.; Fan, W. The role and mechanisms of action of microRNAs in cancer drug resistance. Clin. Epigenetics 2019, 11, 25. [CrossRef]

22. Calin, G.A.; Dumitru, C.D.; Shimizu, M.; Bichi, R.; Zupo, S.; Noch, E.; Aldler, H.; Rattan, S.; Keating, M.; Rai, K.; et al. Frequent deletions and down-regulation of micro- RNA genes miR15 and miR16 at 13q14 in chronic lymphocytic leukemia. Proc. Natl. Acad. Sci. USA 2002, 99, 15524-15529. [CrossRef] [PubMed]

23. Murakami, Y.; Tanahashi, T.; Okada, R.; Toyoda, H.; Kumada, T.; Enomoto, M.; Tamori, A.; Kawada, N.; Taguchi, Y.H.; Azuma, T. Comparison of hepatocellular carcinoma miRNA expression profiling as evaluated by next generation sequencing and microarray. PLoS ONE 2014, 9, e106314. [CrossRef]

24. Wojcicka, A.; Swierniak, M.; Kornasiewicz, O.; Gierlikowski, W.; Maciag, M.; Kolanowska, M.; Kotlarek, M.; Gornicka, B.; Koperski, L.; Niewinski, G.; et al. Next generation sequencing reveals microRNA isoforms in liver cirrhosis and hepatocellular carcinoma. Int. J. Biochem. Cell Biol. 2014, 53, 208-217. [CrossRef] [PubMed]

25. Ghidini, M.; Braconi, C. Non-Coding RNAs in Primary Liver Cancer. Front. Med. (Lausanne) 2015, 2, 36. [CrossRef] [PubMed]

26. Hou, J.; Lin, L.; Zhou, W.; Wang, Z.; Ding, G.; Dong, Q.; Qin, L.; Wu, X.; Zheng, Y.; Yang, Y.; et al. Identification of miRNomes in human liver and hepatocellular carcinoma reveals miR-199a/b-3p as therapeutic target for hepatocellular carcinoma. Cancer Cell 2011, 19, 232-243. [CrossRef] [PubMed]

27. Meng, F.; Henson, R.; Wehbe-Janek, H.; Ghoshal, K.; Jacob, S.T.; Patel, T. MicroRNA-21 regulates expression of the PTEN tumor suppressor gene in human hepatocellular cancer. Gastroenterology 2007, 133, 647-658. [CrossRef]

28. Pineau, P.; Volinia, S.; McJunkin, K.; Marchio, A.; Battiston, C.; Terris, B.; Mazzaferro, V.; Lowe, S.W.; Croce, C.M.; Dejean, A. miR-221 overexpression contributes to liver tumorigenesis. Proc. Natl. Acad. Sci. USA 2010, 107, 264-269. [CrossRef] [PubMed]

29. Toffanin, S.; Alsinet, C.; Cornella, H.; Sia, D.; Llovet, J.M. microRNAs and the MYC network: A major piece in the puzzle of liver cancer. Gastroenterology 2011, 140, 2138-2140. [CrossRef] 
30. Xu, T.; Zhu, Y.; Wei, Q.K.; Yuan, Y.; Zhou, F.; Ge, Y.Y.; Yang, J.R.; Su, H.; Zhuang, S.M. A functional polymorphism in the miR-146a gene is associated with the risk for hepatocellular carcinoma. Carcinogenesis 2008, 29, 2126-2131. [CrossRef] [PubMed]

31. Di Bisceglie, A.M.; Sterling, R.K.; Chung, R.T.; Everhart, J.E.; Dienstag, J.L.; Bonkovsky, H.L.; Wright, E.C.; Everson, G.T.; Lindsay, K.L.; Lok, A.S.; et al. Serum alpha-fetoprotein levels in patients with advanced hepatitis C: Results from the HALT-C Trial. J. Hepatol. 2005, 43, 434-441. [CrossRef]

32. Lok, A.S.; Sterling, R.K.; Everhart, J.E.; Wright, E.E.C.; Hoefs, J.C.; Di Bisceglie, A.M.; Morgan, T.R.; Kim, H.Y.; Lee, W.M.; Bonkovsky, H.L.; et al. Des-gamma-carboxy prothrombin and alpha-fetoprotein as biomarkers for the early detection of hepatocellular carcinoma. Gastroenterology 2010, 138, 493-502. [CrossRef]

33. Hayes, C.N.; Chayama, K. MicroRNAs as Biomarkers for Liver Disease and Hepatocellular Carcinoma. Int. J. Mol. Sci. 2016, 17, 280. [CrossRef]

34. Szabo, G.; Csak, T. Role of MicroRNAs in NAFLD/NASH. Dig. Dis. Sci. 2016, 61, 1314-1324. [CrossRef]

35. Meng, F.L.; Wang, W.; Jia, W.D. Diagnostic and prognostic significance of serum miR-24-3p in HBV-related hepatocellular carcinoma. Med. Oncol. 2014, 31, 177. [CrossRef]

36. Bandiera, S.; Pfeffer, S.; Baumert, T.F.; Zeisel, M.B. miR-122-a key factor and therapeutic target in liver disease. J. Hepatol. 2015, 62, 448-457. [CrossRef]

37. Calin, G.A.; Croce, C.M. Chromosomal rearrangements and microRNAs: A new cancer link with clinical implications. J. Clin. Investig. 2007, 117, 2059-2066. [CrossRef] [PubMed]

38. Ha, M.; Kim, V.N. Regulation of microRNA biogenesis. Nat. Rev. Mol. Cell Biol. 2014, 15, 509-524. [CrossRef]

39. Wang, D.; Sun, X.; Wei, Y.; Liang, H.; Yuan, M.; Jin, F.; Chen, X.; Liu, Y.; Zhang, C.Y.; Li, L.; et al. Nuclear miR-122 directly regulates the biogenesis of cell survival oncomiR miR-21 at the posttranscriptional level. Nucleic Acids Res. 2018, 46, 2012-2029. [CrossRef] [PubMed]

40. Wang, J.; Yu, X.F.; OUYang, N.; Luo, Q.; Tong, J.; Chen, T.; Li, J. Role of DNA methylation regulation of miR-130b expression in human lung cancer using bioinformatics analysis. J. Toxicol. Environ. Health A 2019, 82, 935-943. [CrossRef] [PubMed]

41. Casero, D.; Sandoval, S.; Seet, C.S.; Scholes, J.; Zhu, Y.; Ha, V.L.; Luong, A.; Parekh, C.; Crooks, G.M. Long non-coding RNA profiling of human lymphoid progenitor cells reveals transcriptional divergence of B cell and T cell lineages. Nat. Immunol. 2015, 16, 1282-1291. [CrossRef]

42. Elemeery, M.N.; Badr, A.N.; Mohamed, M.A.; Ghareeb, D.A. Validation of a serum microRNA panel as biomarkers for early diagnosis of hepatocellular carcinoma post-hepatitis C infection in Egyptian patients. World J. Gastroenterol. 2017, 23, 3864-3875. [CrossRef]

43. Zheng, J.; Dong, P.; Gao, S.; Wang, N.; Yu, F. High expression of serum miR-17-5p associated with poor prognosis in patients with hepatocellular carcinoma. Hepatogastroenterology 2013, 60, 549-552. [CrossRef]

44. Sorop, A.; Iacob, R.; Iacob, S.; Constantinescu, D.; Chitoiu, L.; Fertig, T.E.; Dinischiotu, A.; Chivu-Economescu, M.; Bacalbasa, N.; Savu, L.; et al. Plasma Small Extracellular Vesicles Derived miR-21-5p and miR-92a-3p as Potential Biomarkers for Hepatocellular Carcinoma Screening. Front. Genet. 2020, 11, 712. [CrossRef]

45. Li, D.; Liu, X.; Lin, L.; Hou, J.; Li, N.; Wang, C.; Wang, P.; Zhang, Q.; Zhang, P.; Zhou, W.; et al. MicroRNA-99a inhibits hepatocellular carcinoma growth and correlates with prognosis of patients with hepatocellular carcinoma. J. Biol. Chem. 2011, 286, 36677-36685. [CrossRef]

46. Petrelli, A.; Perra, A.; Schernhuber, K.; Cargnelutti, M.; Salvi, A.; Migliore, C.; Ghiso, E.; Benetti, A.; Barlati, S.; Ledda-Columbano, G.M.; et al. Sequential analysis of multistage hepatocarcinogenesis reveals that miR-100 and PLK1 dysregulation is an early event maintained along tumor progression. Oncogene 2012, 31, 4517-4526. [CrossRef]

47. Li, W.; Chang, J.; Wang, S.; Liu, X.; Peng, J.; Huang, D.; Sun, M.; Chen, Z.; Zhang, W.; Guo, W.; et al. miRNA-99b-5p suppresses liver metastasis of colorectal cancer by down-regulating mTOR. Oncotarget 2015, 6, 24448-24462. [CrossRef]

48. Zhang, J.; Jin, H.; Liu, H.; Lv, S.; Wang, B.; Wang, R.; Liu, H.; Ding, M.; Yang, Y.; Li, L.; et al. MiRNA-99a directly regulates AGO2 through translational repression in hepatocellular carcinoma. Oncogenesis 2014, 3, e97. [CrossRef] [PubMed]

49. Li, B.; Huang, P.; Qiu, J.; Liao, Y.; Hong, J.; Yuan, Y. MicroRNA-130a is down-regulated in hepatocellular carcinoma and associates with poor prognosis. Med. Oncol. 2014, 31, 230. [CrossRef] [PubMed]

50. Yang, C.; Xu, Y.; Cheng, F.; Hu, Y.; Yang, S.; Rao, J.; Wang, X. miR-1301 inhibits hepatocellular carcinoma cell migration, invasion, and angiogenesis by decreasing Wnt/beta-catenin signaling through targeting BCL9. Cell Death Dis. 2017, 8, e2999. [CrossRef] [PubMed]

51. Fornari, F.; Milazzo, M.; Chieco, P.; Negrini, M.; Calin, G.A.; Grazi, G.L.; Pollutri, D.; Croce, C.M.; Bolondi, L.; Gramantieri, L. MiR-199a-3p regulates mTOR and c-Met to influence the doxorubicin sensitivity of human hepatocarcinoma cells. Cancer Res. 2010, 70, 5184-5193. [CrossRef]

52. Shatseva, T.; Lee, D.Y.; Deng, Z.; Yang, B.B. MicroRNA miR-199a-3p regulates cell proliferation and survival by targeting caveolin-2. J. Cell Sci. 2011, 124, 2826-2836. [CrossRef]

53. Xu, N.; Zhang, J.; Shen, C.; Luo, Y.; Xia, L.; Xue, F.; Xia, Q. Cisplatin-induced downregulation of miR-199a-5p increases drug resistance by activating autophagy in HCC cell. Biochem. Biophys. Res. Commun. 2012, 423, 826-831. [CrossRef]

54. Li, S.Q.; Wang, Z.H.; Mi, X.G.; Liu, L.; Tan, Y. MiR-199a/b-3p suppresses migration and invasion of breast cancer cells by downregulating PAK4/MEK/ERK signaling pathway. IUBMB Life 2015, 67, 768-777. [CrossRef] 
55. Yu, S.; Jing, L.; Yin, X.R.; Wang, M.C.; Chen, Y.M.; Guo, Y.; Nan, K.J.; Han, L.L. MiR-195 suppresses the metastasis and epithelial-mesenchymal transition of hepatocellular carcinoma by inhibiting YAP. Oncotarget 2017, 8, 99757-99771. [CrossRef]

56. Shih, T.C.; Tien, Y.J.; Wen, C.J.; Yeh, T.S.; Yu, M.C.; Huang, C.H.; Lee, Y.S.; Yen, T.C.; Hsieh, S.Y. MicroRNA-214 downregulation contributes to tumor angiogenesis by inducing secretion of the hepatoma-derived growth factor in human hepatoma. J. Hepatol. 2012, 57, 584-591. [CrossRef]

57. Wang, X.; Chen, J.; Li, F.; Lin, Y.; Zhang, X.; Lv, Z.; Jiang, J. MiR-214 inhibits cell growth in hepatocellular carcinoma through suppression of beta-catenin. Biochem. Biophys. Res. Commun. 2012, 428, 525-531. [CrossRef]

58. Zhang, X.; Yu, B.; Zhang, F.; Guo, Z.; Li, L. microRNA-18a Promotes Cell Migration and Invasion Through Inhibiting Dicer 1 Expression in Hepatocellular Carcinoma In Vitro. Chin. Med. Sci. J. 2017, 32, 34-43. [CrossRef] [PubMed]

59. Zhou, Y.; Ren, H.; Dai, B.; Li, J.; Shang, L.; Huang, J.; Shi, X. Hepatocellular carcinoma-derived exosomal miRNA-21 contributes to tumor progression by converting hepatocyte stellate cells to cancer-associated fibroblasts. J. Exp. Clin. Cancer Res. 2018, 37, 324 . [CrossRef] [PubMed]

60. Huang, J.T.; Liu, S.M.; Ma, H.; Yang, Y.; Zhang, X.; Sun, H.; Zhang, X.; Xu, J.; Wang, J. Systematic Review and Meta-Analysis: Circulating miRNAs for Diagnosis of Hepatocellular Carcinoma. J. Cell. Physiol. 2016, 231, 328-335. [CrossRef] [PubMed]

61. Yuan, Q.; Loya, K.; Rani, B.; Mobus, S.; Balakrishnan, A.; Lamle, J.; Cathomen, T.; Vogel, A.; Manns, M.P.; Ott, M.; et al. MicroRNA-221 overexpression accelerates hepatocyte proliferation during liver regeneration. Hepatology 2013, 57, $299-310$. [CrossRef]

62. Fu, Y.; Liu, M.; Li, F.; Qian, L.; Zhang, P.; Lv, F.; Cheng, W.; Hou, R. MiR-221 Promotes Hepatocellular Carcinoma Cells Migration via Targeting PHF2. BioMed Res. Int. 2019, 2019, 4371405. [CrossRef]

63. Galardi, S.; Mercatelli, N.; Giorda, E.; Massalini, S.; Frajese, G.V.; Ciafre, S.A.; Farace, M.G. miR-221 and miR-222 expression affects the proliferation potential of human prostate carcinoma cell lines by targeting p27Kip1. J. Biol. Chem. 2007, 282, 23716-23724. [CrossRef]

64. Lan, S.H.; Wu, S.Y.; Zuchini, R.; Lin, X.Z.; Su, I.J.; Tsai, T.F.; Lin, Y.J.; Wu, C.T.; Liu, H.S. Autophagy suppresses tumorigenesis of hepatitis B virus-associated hepatocellular carcinoma through degradation of microRNA-224. Hepatology 2014, 59, 505-517. [CrossRef] [PubMed]

65. Visone, R.; Russo, L.; Pallante, P.; de Martino, I.; Ferraro, A.; Leone, V.; Borbone, E.; Petrocca, F.; Alder, H.; Croce, C.M.; et al. MicroRNAs (miR)-221 and miR-222, both overexpressed in human thyroid papillary carcinomas, regulate p27Kip1 protein levels and cell cycle. Endocr. Relat. Cancer 2007, 14, 791-798. [CrossRef] [PubMed]

66. Yuan, B.; Dong, R.; Shi, D.; Zhou, Y.; Zhao, Y.; Miao, M.; Jiao, B. Down-regulation of miR-23b may contribute to activation of the TGF-beta1/Smad3 signalling pathway during the termination stage of liver regeneration. FEBS Lett. 2011, 585, 927-934. [CrossRef]

67. Qi, P.; Cheng, S.Q.; Wang, H.; Li, N.; Chen, Y.F.; Gao, C.F. Serum microRNAs as biomarkers for hepatocellular carcinoma in Chinese patients with chronic hepatitis B virus infection. PLOS ONE 2011, 6, e28486. [CrossRef]

68. Xu, J.; Wu, C.; Che, X.; Wang, L.; Yu, D.; Zhang, T.; Huang, L.; Li, H.; Tan, W.; Wang, C.; et al. Circulating microRNAs, miR-21, miR-122, and miR-223, in patients with hepatocellular carcinoma or chronic hepatitis. Mol. Carcinog. 2011, 50, 136-142. [CrossRef]

69. Zhou, J.; Yu, L.; Gao, X.; Hu, J.; Wang, J.; Dai, Z.; Wang, J.F.; Zhang, Z.; Lu, S.; Huang, X.; et al. Plasma microRNA panel to diagnose hepatitis B virus-related hepatocellular carcinoma. J. Clin. Oncol. 2011, 29, 4781-4788. [CrossRef] [PubMed]

70. Gramantieri, L.; Ferracin, M.; Fornari, F.; Veronese, A.; Sabbioni, S.; Liu, C.G.; Calin, G.A.; Giovannini, C.; Ferrazzi, E.; Grazi, G.L.; et al. Cyclin G1 is a target of miR-122a, a microRNA frequently down-regulated in human hepatocellular carcinoma. Cancer Res. 2007, 67, 6092-6099. [CrossRef]

71. Jampoka, K.; Muangpaisarn, P.; Khongnomnan, K.; Treeprasertsuk, S.; Tangkijvanich, P.; Payungporn, S. Serum miR-29a and miR-122 as Potential Biomarkers for Non-Alcoholic Fatty Liver Disease (NAFLD). Microrna 2018, 7, 215-222. [CrossRef] [PubMed]

72. Cheung, O.; Puri, P.; Eicken, C.; Contos, M.J.; Mirshahi, F.; Maher, J.W.; Kellum, J.M.; Min, H.; Luketic, V.A.; Sanyal, A.J. Nonalcoholic steatohepatitis is associated with altered hepatic MicroRNA expression. Hepatology 2008, 48, 1810-1820. [CrossRef] [PubMed]

73. Cheng, J.; Chen, Y.; Zhao, P.; Liu, X.; Dong, J.; Li, J.; Huang, C.; Wu, R.; Lv, Y. Downregulation of miRNA-638 promotes angiogenesis and growth of hepatocellular carcinoma by targeting VEGF. Oncotarget 2016, 7, 30702-30711. [CrossRef]

74. Tsai, W.C.; Hsu, S.D.; Hsu, C.S.; Lai, T.C.; Chen, S.J.; Shen, R.; Huang, Y.; Chen, H.C.; Lee, C.H.; Tsai, T.F.; et al. MicroRNA-122 plays a critical role in liver homeostasis and hepatocarcinogenesis. J. Clin. Investig. 2012, 122, 2884-2897. [CrossRef]

75. Singh, G.; Yoshida, E.M.; Rathi, S.; Marquez, V.; Kim, P.; Erb, S.R.; Salh, B.S. Biomarkers for hepatocellular cancer. World J. Hepatol. 2020, 12, 558-573. [CrossRef] [PubMed]

76. Wan, H.G.; Xu, H.; Gu, Y.M.; Wang, H.; Xu, W.; Zu, M.H. Comparison osteopontin vs AFP for the diagnosis of HCC: A meta-analysis. Clin. Res. Hepatol. Gastroenterol. 2014, 38, 706-714. [CrossRef]

77. Xu, X.; Tao, Y.; Shan, L.; Chen, R.; Jiang, H.; Qian, Z.; Cai, F.; Ma, L.; Yu, Y. The Role of MicroRNAs in Hepatocellular Carcinoma. J. Cancer 2018, 9, 3557-3569. [CrossRef]

78. Ma, R.; Zhao, M.; Zou, X.; Zhou, J.; Bai, Z. MicroRNA polymorphism: A target for diagnosis and prognosis of hepatocellular carcinoma? Oncol. Lett. 2021, 21, 324. [CrossRef]

79. Jiang, Y.; He, J.; Li, Y.; Guo, Y.; Tao, H. The Diagnostic Value of MicroRNAs as a Biomarker for Hepatocellular Carcinoma: A Meta-Analysis. Biomed. Res. Int. 2019, 2019, 5179048. [CrossRef] 